\title{
Modelos de renovación en las series de televisión juveniles de producción española. Estudio de caso de Merlí (TV3, 2015) y Skam España (Movistar, 2018)
}

\section{New trends in Spanish-produced television series for young audiences. A case study of Merlí (TV3, 2015) and Skam España (Movistar, 2018)}

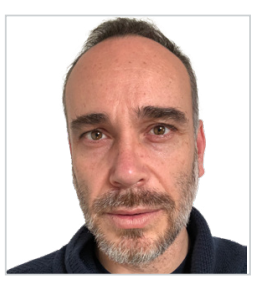

Javier Mateos-Pérez. Profesor e Investigador Posdoctoral en el Departamento de Periodismo y Comunicación Global de la Universidad Complutense de Madrid, e Investigador Principal del proyecto de investigación (20202024): "Las series de televisión españolas del siglo XXI. Narrativas, estéticas, representaciones históricas y sociales" 2019-T1/SOC-12886, financiado por el Programa de Atracción al Talento Investigador de la Comunidad de Madrid. Modalidad 1. Doctores con Experiencia. Ha sido profesor Titular en el Instituto de la Comunicación e Imagen de la Universidad de Chile, donde también fue director de Investigación y Editor General de la publicación científica Comunicación y Medios. Su investigación académica se centra la imagen, las narrativas audiovisuales y el estudio de la televisión: programas, programación y ficción televisiva.

Universidad Complutense de Madrid, España

jmateosperez@ucm.es

ORCID: 0000-0003-2056-8704

Recibido: 25/10/2020 - Aceptado: 07/04/2021 - En edición: 05/05/2021 - Publicado: 14/06/2021 Resumen:

Este trabajo es una aproximación a la ficción televisiva de producción española del siglo XXI protagonizada por jóvenes. Se seleccionan dos series juveniles recientes: Merlí (TV3, 2015) y Skam España (Movistar, 2018), y a través del estudio de caso se relacionan aportaciones teóricas sobre la representación juvenil en la ficción televisiva, se determina la evolución del género y se resaltan sus principales innovaciones. Para el análisis se emplea una metodología de corte cualitativo y como técnica se escoge el análisis textual de las series con el fin de reconstruir las principales claves del contenido, narrativo y audiovisual. Las conclusiones propuestas distinguen diferentes estrategias en cada serie:
Received: 25/10/2020 - Accepted: 07/04/2021 - Early access: 05/05/2021 - Published: 14/06/2021 Abstract:

This study investigates Spanish television fiction starring young people produced in the 21st century. Two recent series for young viewers were selected, namely, Merlí (TV3, 2015) and Skam España (Movistar, 2018). These case studies are used to provide theoretical insights into youth representations in television fiction to explain how the genre has evolved and what have been its main innovations. The analysis employed a qualitative methodology, and text analysis of the series was chosen to reconstruct the key aspects of their narrative and audio-visual content. The conclusions identify different strategies in each series: narrative and aesthetic strategies; and strategies related to production, distribution and narrative

1 Este trabajo forma parte del Proyecto de Investigación: “Las series españolas de televisión del siglo XXI. Narrativas, estéticas, representaciones históricas y sociales". Investigación financiada por el Programa de Atracción al Talento Investigador de la Comunidad de Madrid. REF. 2019 -T1/SOC-12886.

Cómo citar este artículo:

Mateos-Pérez, J. (2021). Modelos de renovación en las series de televisión juveniles de producción española. Estudio de caso de Merlí (TV3, 2015) y Skam España (Movistar, 2018). Doxa Comunicación, 32, pp. 143-157.

https://doi.org/10.31921/doxacom.n32a7 
narrativas y estéticas; y de producción, distribución y extensión narrativa. El conjunto permite observar la renovación en las series juveniles españolas y subraya el uso de distintas significaciones sobre la adolescencia fijadas en la ficción española actual. Palabras clave:

Series de televisión; España; plataformas VOD; ficción televisiva juvenil; jóvenes. extension. These two series illustrate the new trends in Spanish series for young audiences and underline the use of different meanings about adolescence present in current Spanish fiction.

Keywords:

TV series; Spain; VOD platforms; TV fiction for young audiences; Young people.

\section{Introducción y estado de la cuestión}

En este estudio se consideran las series de televisión juveniles, de producción española, adscritas al formato dramático y protagonizadas por jóvenes. Estos relatos se organizan a partir de tramas realistas que aluden a temas que conciernen a los jóvenes y se contextualizan en espacios y contextos propios de este estrato. El centro de enseñanza como centro neurálgico, los hogares de los protagonistas y el entorno urbano son los principales espacios de la acción. Por ellos transita un elenco de personajes variados que responden a distintos perfiles, estilos de vida e identificaciones del público. Además, estos lugares permiten expandir el abanico de personajes hacia el segmento adulto posibilitando con ello la ampliación de la audiencia también hacia ese público. Estos dramas sociales son significativos porque componen un retrato generacional y propician una reflexión sobre el mundo juvenil al reconstruir de forma naturalista la sociedad en la que se inscriben.

Las obras televisivas de ficción juveniles se dividen en dos segmentos. El primero se compone de las series sobre jóvenes que se dirigen específicamente a esa audiencia desde la cultura juvenil. Estas son calificadas como teen series (Raya, Sánchez-Labella \& Durán, 2018; Navarro \& Climent, 2014). Este fenómeno se concreta en la ficción televisiva, que abastece parte de la programación de cadenas generalistas y copa los contenidos de canales temáticos de televisión que tienen a los jóvenes como público potencial (García \& Fedele, 2011). El segundo aglutina aquellas series que, a pesar de que el mayor peso narrativo sigue recayendo en los protagonistas jóvenes, también incorporan personajes, temas y tramas que conciernen a otras edades, como adultos, niños o tercera edad. Algunas de estas series también pueden inscribirse en los denominados "dramas familiares", subgénero que se dirige a toda la familia e incluye a sus miembros en las tramas (Hidalgo-Marí \& de la Cuadra, 2020: 637).

El fenómeno televisivo ficcional juvenil aprovechó la evolución tecnológica y la sabiduría generacional de los adolescentes para enlazarlos con nuevas pantallas (Guarinos, 2009:205). Los jóvenes pasaron a ser un segmento atractivo para los programadores al verlos como potenciales consumidores y aplicados con las tecnologías. Los canales generalistas articularon un entramado multimedia alrededor de las series y a través de los soportes en línea con el objetivo de hacer uso de estrategias de promoción, ofrecer mayores oportunidades de visionado y fidelizar al público. Este entorno transmedia lo aprovecharon las audiencias jóvenes participativas para compartir gustos e inquietudes, extender las narrativas y para mostrar sus relatos fuera de los cauces comerciales (Galán \& Del Pino, 2010). El consumo audiovisual se generalizó más 
allá de la televisión, hacia otras pantallas: móviles, tabletas, ordenadores, lo que aumentó la dinámica de los jóvenes de ver contenidos audiovisuales. En especial se interesaron por las series de ficción, con un aumento de la oferta exponencial desde el establecimiento de las plataformas VOD y los visionados por internet. Con todo, los jóvenes tuvieron a su alcance la tecnología como para decidir qué ver, y dónde y cuándo hacerlo.

Según los estudios sobre los efectos de los medios, las series de televisión ejercen influencia sobre la personalidad, los comportamientos y los valores del público. En particular sobre el segmento juvenil, puesto que este se encuentra en la fase del desarrollo humano en la que se construye su identidad personal. Existen estudios que aluden a la recepción, a los usos y efectos que producen las series en los jóvenes (Medrano, Airbe y Martínez de Moretin, 2011). Estas investigaciones sostienen que los personajes de las series influyen a los jóvenes (Jinadasa, 2015; Bermejo, 2012; Pindado, 2006). Estos adquieren -a través de la mímesis e identificación-actitudes, comportamientos, valores, creencias y metas que se proponen desde estos relatos televisivos (Hoffner y Buchanan, 2005; Cohen, 2006). Otros de los temas recurrentes sobre los efectos emanan de la terna de representación: imagen, sexualidad y violencia. Así, se ha investigado la imagen que proyectan los jóvenes en el horario de máxima audiencia (Heintz-Knowles, 2000); la representación de la violencia (González, 2012); la conducta sexual de los personajes jóvenes (Aubrey, 2004; Meyer, 2003); las lecturas de los jóvenes sobre las relaciones sexuales y afectivas mostradas en series españolas (Figueras, Tortajada \& Arana, 2014), y la representación de la sexualidad en la ficción seriada dirigida a los jóvenes (Masanet, Medina \& Ferrés, 2012). Incluso, se ha propuesto una base metodológica para un análisis sistemático del contenido sexual en las series para adolescentes (Crespo, 2005).

En el último tiempo se han constituido otras propuestas más integradas, como las que aluden a la educomunicación y al eduentretenimiento. Estas también colocan el foco sobre la relación entre jóvenes y televisión de entretenimiento, donde se localizan contenidos educativos relacionados con la salud o la ciencia (Gutiérrez, 2019; Grande, 2019; Villa, 2012).

La ficción televisiva ha mostrado de forma habitual la transición de la niñez a la vida adulta contribuyendo a la creación de un conjunto de estereotipos en torno a la figura del adolescente. Por ello se han analizado los prototipos de adolescentes en los productos de ficción españoles (Guarinos, 2009) y, en particular, los masculinos (Guarinos, et al. 2010). También se ha estudiado el estereotipo del joven inadaptado social y su evolución hacia una concepción posmoderna donde muta en héroe con la cualidad de la autorreflexividad (García, 2011). Esta tendencia a la actualización de la individualidad y la diferencia es un tema característico de los relatos adolescentes que en los últimos años Netflix ha empleado con el objeto de visibilizar problemáticas como el bullying o el autismo (Raya, Sánchez-Labella \& Durán, 2018).

El estudio sobre la representación de los jóvenes en la ficción televisiva española de mayor entidad considerando la muestra -516 personajes- recoge el bienio final de la primera década del nuevo siglo (Lacalle, 2013). Siguiendo esta investigación, se observan claves sobre el relato que permiten establecer las características propias de este tipo de series. Por ejemplo, el relato destaca por su organización lineal, por su construcción a través de la perspectiva de distintos personajes, por cuidar la puesta en escena y por poner de manifiesto la objetividad en el montaje, evidenciando el desinterés por la retórica de la imagen (Lacalle, 2013: 140-153). 


\section{Objetivos, hipótesis, metodología y objeto}

El artículo que aquí se presenta supone una aproximación a la ficción televisiva protagonizaba por adolescentes a través del estudio de caso de dos series juveniles recientes: Merlí (TV3, 2015) y Skam España (Movistar, 2018). La hipótesis de partida es que ambas obras proponen una serie de innovaciones que renuevan y actualizan la ficción juvenil de producción nacional. Estas innovaciones aluden a las narrativas y a las estéticas, así como a la producción y a la emisión de este tipo de producciones.

El objetivo del presente trabajo es determinar la evolución del formato. Para ello, se estudian antecedentes y se analizan en profundidad dos series actuales aplicando el estudio de caso.

Para realizar el análisis se ha empleado una metodología cualitativa. Como técnica se escoge el Análisis Textual, que atiende a elementos concretos del texto y a los modos en que dicho texto se construye. Con este fin se ha creado una ficha de análisis (Tabla 1) como recurso, que organiza y recopila los datos extraídos sobre las obras. Finalmente, se dirige el interés hacia el modo de interpretar su significado en un sentido global, valorizando tanto los temas de los que se habla como las formas de enunciación del propio discurso (Casetti \& Di Chio, 1999: 149-151).

Tabla 1

\begin{tabular}{|l|l|}
\hline \multicolumn{2}{|c|}{ 1. Contexto de las STV } \\
\hline Datos de identificación & $\begin{array}{l}\text { Fichas técnicas y creativas; años de producción y de } \\
\text { programación; canales de difusión }\end{array}$ \\
\hline Clasificación & Géneros; formatos y tipologías \\
\hline \multicolumn{2}{|c|}{ 2. Aspectos narrativos } \\
\hline Temas & Primarios y secundarios \\
\hline Tramas & Generales y específicas \\
\hline Estructura dramática & Confrontación, desarrollo y final \\
\hline Instancias narradoras & Narrador/res, perspectivas y puntos de vista \\
\hline Personajes & Descripción física y psicológica; rol/es y conflicto/s \\
\hline & \multicolumn{1}{c|}{ 3. Aspectos formales } \\
\hline Códigos icónicos & Planos; movimientos de cámara; encuadres \\
\hline Códigos sonoros & Funciones y cabecera \\
\hline Códigos gráficos & Créditos e indicadores de contexto de la serie \\
\hline Códigos sintácticos & Montaje \\
\hline & \multicolumn{2}{|c|}{ 4. Interpretación } \\
\hline
\end{tabular}

Fuente: elaboración propia.

El objeto de investigación seleccionado son las series Merlíy Skam España. Las dos son de producción española. Merlífue emitida en catalán por la televisión autonómica TV3 entre el 14 de septiembre de 2015 y el 15 de enero de 2018. La serie se 
dobló al español para emitirse temporalmente en LaSexta, entre abril y julio de 2016, y en el canal Neox, entre 2017 y 2018. En la actualidad se localiza en el catálogo de Netflix. Consta de 40 capítulos, de 50 minutos de duración cada uno, distribuidos en 3 temporadas. Skam España se estrenó el 16 de septiembre de 2018 en la plataforma Movistar. En la actualidad se han emitido 38 episodios, que oscilan entre los 20 y los 40 minutos de duración. Estos se distribuyen en 4 temporadas.

Ambas series están protagonizadas por adolescentes y narran de forma realista las historias de sendos grupos de estudiantes de institutos de secundaria localizados, uno en Madrid y el otro en Barcelona. Las dos han representado un fenómeno mediático expansivo - Merlí en América Latina, Skam en Europa- ofreciendo alternativas al mercado hegemónico estadounidense, lo que brinda un interés especial por comprender el mensaje que transmiten.

A pesar de estas semejanzas, las propuestas son diferentes. Merlí es una serie original creada por Héctor Lozano y producida por una televisión autonómica que la programó con éxito de público -fue líder de su franja horaria con una cuota de audiencia de $18 \%$ - en horario de máxima audiencia. Se trata de un relato actual sobre la juventud, aunque no desdeña a otras audiencias, por lo que inserta también personajes protagonistas adultos con equivalente peso narrativo. La repercusión positiva de la serie motivó una continuación Merlí, Sapere Aude (Movistar, 2020), con el seguimiento de algunos de sus personajes en el paso de los estudios secundarios a los universitarios. Por el contrario, Skam España es una adaptación española de la serie noruega Skam, creada por Julie Andem, y está producida por Movistar. Además de disponer de todos los contenidos en la plataforma de pago, el acceso a la serie pudo concretarse, además, a través de las redes sociales, aunque de forma fragmentada. También ofrece un retrato juvenil actual, aunque en este caso se centra en un grupo femenino de compañeras y reserva para los personajes adultos papeles secundarios.

El trabajo se ha organizado en dos fases. Un primer visionado de la muestra intencional y un segundo visionado de análisis. Se ha sumado la serie noruega Skam, con el fin de determinar las diferencias entre la serie original y la versión española; y Merlí Sapere Aude, spin-off de Merlí, con la intención de observar la ampliación narrativa de la original. Los visionados y analíticas de las series antecedentes y precedentes han servido para comparar su contenido con el de las nuevas producciones.

\section{Series españolas de ficción televisiva juvenil. Los antecedentes}

El primer antecedente es Verano azul (TVE, 1981), producida y dirigida por Antonio Mercero. Se trata de un hilo de memoria colectiva de los años ochenta que agrietó los esquemas de la televisión franquista con su tratamiento abierto y sin complejos de temas adolescentes. El relato acompañaba las vacaciones de verano de una pandilla de chicas y chicos en la Costa del Sol y profundizaba en sus relaciones sociales y familiares. Mercero, poseía experiencia tanto en televisión (Crónicas de un pueblo, TVE, 1971; Este señor de negro, TVE, 1975) como en cine, donde había ensayado diversos proyectos cuyos personajes protagonistas eran menores (La guerra de papá, 1977; Toby, 1978). La repercusión fue notable. Verano azul se considera un título emblemático de la ficción de la cadena pública, y aún se sigue reponiendo (Bazán \& Sastre, 2014). La importancia se calibra observando que la muerte del personaje Chanquete la recogieron en primera plana los periódicos nacionales al día siguiente como si de una persona real se tratase. Si bien la serie estaba pensada para una audiencia generalista, la mayor parte de los temas y las tramas aludían a los jóvenes, que eran los protagonistas del relato. 
Cinco años más tarde se emite Segunda enseñanza (TVE, 1986), escrita por Ana Diosdado, y producida y dirigida por Pedro Masó. Esta dupla venía de producir la exitosa y aperturista Anillos de oro (TVE, 1983) después de que se aprobara la Ley que permitía el divorcio en España. Ensayó a continuación otra representación social de su tiempo situando la obra en un colegio de Oviedo, con Diosdado como profesora y un grupo de estudiantes personificados por la generación de intérpretes jóvenes del momento: Ana Torrent, Jorge Sanz, Aitana Sánchez-Gijón, Gabino Diego o Javier Bardem, entre otros. La serie sitúa parte de su narración en el Colegio Santullano, un centro innovador que promueve un sistema de enseñanza entonces atípico: los padres son accionistas, los maestros cercanos y los estudiantes opinan y cuestionan sobre los contenidos y las metodologías de aprendizaje. A lo largo de los 13 capítulos, de entre 50 y 60 minutos cada uno, aparecen y se desarrollan temas que interpelan a los jóvenes, como el respeto a las creencias, el consumo de drogas, el interés por aprender, la adscripción a los estereotipos, el uso de la violencia, etcétera. La narración se expande hacia las familias de los diferentes personajes, completando un fresco generacional en un momento de cambio social y modernización incipiente. Segunda enseñanza formal y narrativamente contiene características propias de la ficción televisiva adolescente o del drama familiar, pero no es una serie que se dirija solo a los jóvenes. Parece relacionarse más con el aprendizaje sobre la vida en la madurez de la profesora y los jóvenes que la rodean cumplen el rol de ayudarla en dicho proceso.

A pesar de que estas series se emitieron en los ochenta, se considera la década de los noventa como el momento en el cual las emisoras comienzan a reparar en unas audiencias hasta entonces residuales: las juveniles. Con afán de acumular la mayor cantidad posible de telespectadores y observando la valoración positiva que los anunciantes profesaban al estrato adolescente, las nuevas cadenas programan contenidos dirigidos a atraerlo. Se trataba de un menú uniforme, profuso en publicidad, escaso en creatividad, que ofertaba concursos, programas musicales y, sobre todo, contenidos enlatados (Mateos-Pérez, 2012). Entre estos últimos, los que más seguimiento acapararon fueron las series de ficción protagonizadas por jóvenes, la mayor parte de ellas importadas. De partida, TVE apostó por Degrassi Junior High (CBC, 1987); Tele 5 por Family Ties (NBC, 1982) y Doogie Howser, M.D. (ABC, 1989) y Canal Plus amplió la oferta con Head of the Class (ABC, 1986); Press Gang (ITV, 1989) y Full House (ABC, 1987). Fue Tele 5 la que acierta emitiendo el éxito del periodo: Beverly Hills, 90210 (Fox, 1990). Una serie dramática, realista, emitida en horario de máxima audiencia, protagonizada por personajes jóvenes, pudientes, atractivos y enmarcada en un instituto de Los Ángeles. Esta serie, creada por Darren Star y producida por Aaron Spelling, ganó popularidad en Estados Unidos y también en España, donde congregaba hasta 5 millones de espectadores por episodio (Ecotel, 1992). Los miembros del elenco artístico no tardaron en saltar a las portadas de revistas para adolescentes. El éxito de convocatoria de Sensación de vivir motivó su continuidad con Melrose Place (Fox, 1992) -incluía un croosover de protagonistas en los primeros capítulos con intención de trasvasar audiencias- y estableció un modelo que no ha dejado de replicarse con diferentes formas desde entonces. Una ficción dramática protagonizada por un grupo de jóvenes, que parte sobre el escenario común de un instituto situado en un entorno urbano y después se desplegaba hacia las familias de cada personaje protagonista con el objetivo de darles profundidad y de situarles en un contexto. Los temas expuestos en la serie se extraían de una determinada realidad actual, planteándolos a través de tramas que abrían conflictos de toda índole, pero inherentes a la juventud.

Los nuevos canales privados apostaron por series extranjeras al comienzo, pero después produjeron sus propios relatos sobre adolescentes. Los títulos más destacados en el cambio de siglo fueron: Al salir de clase (Tele 5, 1997) y Compañeros 
(Antena 3, 1998). La primera la produce Boca a Boca y la dirige Antonio Cuadri. La serie se presenta en un formato diario, dramático, de 25 minutos por capítulo, que se integra en la parrilla en el bloque de sobremesa, tradicionalmente coto vedado de magacines de tarde y de telenovelas y soap opera a las que acabaron imitando. Al salir de clase comenzó pegándose a la realidad para contar las vidas y relaciones de un puñado de estudiantes del instituto Siete Robles, pero debido a su emisión diaria sin apenas descansos -cinco años, 1.199 episodios-, las tramas, los personajes y hasta el género de la serie iba modificándose y/o complicándose hasta la extenuación. Carlos Moreno, creador de Élite y miembro del equipo de guionistas de 1997 a 1999, da cuenta de las oscilaciones de la narrativa del proyecto y apunta datos sobre el sistema de trabajo de creación: "Llegué en la tercera temporada, cuando las tramas ya eran loquísimas, como ocurre en cualquier serie diaria. Trabajábamos en bloques de cinco capítulos, con muy poco tiempo. Fue todo un aprendizaje. Perdí el miedo a la página en blanco. Lo importante era producir, porque la maquinaria no podía parar" (Llanos, 2018). Esta serie sirvió a guionistas, realizadores, y actores como medio para acceder a nuevos proyectos de ficción, teatrales, televisivos y cinematográficos. Nombres como Sergio Peris Mencheta, Pilar López de Ayala, Rubén Ochandiano, Hugo Silva, Leticia Dolera o Rodolfo Sancho son ejemplo de ello.

Compañeros fue un proyecto de Globomedia. Esta producción aspiraba a un público de mayor edad que la audiencia juvenil. Se programó los miércoles, con una duración de 65-75 minutos, y centró el relato sobre un grupo de compañeros del colegio concertado Azcona. Para adecuarlo a todos los públicos introdujeron personajes adultos que asumían papeles de profesores y progenitores. Los temas se ajustaban a la realidad -y actualidad-adolescente, proponiendo tópicos de las series sobre jóvenes: racismo, agresiones sexuales, embarazos no deseados, consumo de drogas, etcétera. Para alcanzar las nueve temporadas, 122 capítulos, hubieron de improvisarse narrativas cada vez más complejas y revitalizar las estéticas: incremento de planos por minuto, saltos de cámara, uso de stedycam22 para ofrecer mayor dinamismo. La extensión narrativa de la serie se vehiculó a través del cine, con el estreno de No te fallaré (Manuel Ríos San Martín, 2001), una cinta para incondicionales que permitía atisbar la evolución de los compañeros años después.

Posteriormente aparecen un conjunto de series protagonizadas por jóvenes: SMS-Sin miedo a soñar (La Sexta, 2006); El Internado (Antena 3, 2007); Física o Química (Antena 3, 2008); Los protegidos (Antena 3, 2010), que alteran el formato, pero mantienen el molde narrativo. Estos títulos proporcionaron índices de audiencia relevantes y trascendieron del mercado español para importarse a otros países, mediante la emisión de la serie original o a través de su adaptación.. Como acompañamiento a los relatos se establecen entramados transmedia con el fin de promocionar, fidelizar a su audiencia y extender las narrativas de las series. Estas producciones, como recientemente Élite (Netflix, 2018), también se proponen contar las vidas y peripecias de grupos de estudiantes que gravitan alrededor de un centro educativo. Sin embargo, la novedad es la acusada hibridación de géneros en su diseño y el añadido de temáticas y personajes que proponen desarrollos narrativos heterogéneos, despegados de la realidad y de la actualidad al supeditarse a géneros de probado éxito televisivo -y que también forman parte de la cultura teen- como el thriller, el terror, el misterio o lo fantástico. En estos casos, el componente social de las series se difumina en detrimento de historias espectaculares, tramas poco convencionales y personajes hiperbólicos. Además, no escatiman en la representación de contenido sexual y violento con cuidada puesta en escena. El reclamo para el acceso de otras audiencias distintas a los jóvenes ahora se produce por la mistura de los géneros. 
Existen otras propuestas: La pecera de Eva (Tele 5, 2010); Pulseras rojas (TV3, 2011); Merlí (TV3, 2015); Skam España (Movistar, 2018); Merlí, Sapere Aude (Movistar, 2019) o HIT (TVE, 2020) donde se atisban nuevas tendencias e innovaciones, en la emisión, en los formatos, en las narrativas y, en algún caso, también en las estéticas. Este grupo de series proponen relatos realistas, que se nutren de problemáticas sociales y se aderezan con referencias actuales.

Este estudio propone el análisis de dos de estas propuestas de televisión juvenil contemporáneas. Ambas funcionan como modelos dispares, pero a la vez alternativos y complementarios, lo que permite observar elementos diversos que apuntan al contenido, a la producción y a la emisión como claves en la renovación en las series juveniles españolas.

\section{Merlí. Educación, filosofía y punto de vista masculino para todos los públicos}

Merlí es una serie creada y producida por Veranda TV -Grupo Godó y Boomerang TV-y emitida por la cadena autonómica TV3. Escrita por Héctor Lozano, curtido en los equipos de guion: Jet lag (TV3, 2001), Vendeplà (TV3, 2005) y La Riera (TV3, 2010), y dirigida por Eduard Cortés. El proyecto surge de la conversación con un amigo profesor de literatura que le explica cómo motiva y trabaja con sus alumnos (Solà, 2015).

Se inscribe en el género de dramedia y, aunque fue una serie concebida para el publico juvenil, ha llegado a capturar una audiencia familiar. Se trata de uno de los productos más emblemáticos de la televisión autonómica en los últimos años: rodada en catalán y dirigida para el público que habita en ese territorio. En 2015 Atresmedia se hace con los derechos de la serie, la dobla al castellano y la emite -primero en La Sexta y después en Neox- a una audiencia nacional. Sin dar importancia a los resultados irregulares del seguimiento de público en la cadena privada, la adquiere Netflix en 2016 para su catálogo de América Latina y de habla hispana en los Estados Unidos. La plataforma funcionó como lanzadera internacional para la serie, convirtiéndose en una de las producciones más vistas de Netflix en el 2017 y en un fenómeno popular en países del cono sur como Chile, Argentina o Uruguay. TVE y la ETB -que la dobla al euskera- también consiguen sus derechos de emisión mientras se prepara una adaptación en Alemania. Toda esta trayectoria fue aval suficiente para que Movistar y TV3 cerraran un acuerdo en 2018 para continuar la serie. El nuevo proyecto mantiene a Lozano en la creación, y destina un mayor presupuesto a la producción de capítulos que se graban con menor duración. Merlí: Sapere Aude (Atrévete a saber), cuya primera temporada se pudo visionar en exclusiva en la plataforma de pago Movistar-finales de 2019-, y en abierto por TV3 un año después de su estreno.

A la serie le da título el nombre de un profesor de filosofía del instituto público Ángel Guimerà de Barcelona. Merlí Bergeron, contestatario y de moral propia, impacta en la vida de sus estudiantes gracias a su personalidad, su compromiso, su lenguaje directo y a técnicas pedagógicas tan innovadoras como poco frecuentes -al estilo de Deads Poets Society, Peter Weir, 1989-. El objetivo es enseñar a los estudiantes a pensar, por lo que los capítulos se estructuran sobre un concepto filosófico que Merlí explica y debate en clase, y después se desarrolla de forma gráfica en la vida de los personajes. Este planteamiento didáctico -eco de la novela El mundo de Sofía del noruego Jostein Gaarder, 1991- que ofrece una aplicación práctica y tangible de la filosofía, resulta uno de los principales hallazgos que plantea la serie. De hecho, su influjo ha sido tal, que desde la emisión de Merlí ha aumentado la preinscripción y matriculación en grados de filosofía localizados en Cataluña entre 2015 y 2017 (Martínez \& Rodó de Zárate, 2020). 
Entre los temas que surgen en la serie se subrayan los que aluden a la actualidad y proponen la reflexión social sobre el presente. En el aula se proponen asuntos como la crisis económica y sus consecuencias: los desahucios, el rescate público a la banca, el desempleo o la corrupción política. Llama la atención el tratamiento crítico que se hace de la situación política de Cataluña y la valoración cómica que dispensa a los nacionalismos -en particular, al catalán-, considerando que la serie se emite en un canal público cuyo poder durante el periodo de producción ha sido detentado por partidos independentistas. También merecen atención las críticas al sistema educativo, a la depauperada clase política o a la religión. Otros temas habituales refieren al amor, la sexualidad, la infidelidad, la amistad o la familia. También se tratan de forma permanente problemas generacionales: la maternidad prematura, la adicción a las drogas, el ciberbullying, etcétera.

La serie acentúa el protagonismo de su personaje principal desde el título. Merlí Bergeron es crítico, posee valores progresistas en cuestiones políticas y sociales y está seguro de sí mismo. Acepta con naturalidad la homosexualidad de su hijo, se muestra integrador con una docente trans pero también destaca por una ética cuestionable, por su machismo permanente y por sus actitudes sexistas antropocéntricas (Bonavitta \& de Garay, 2019: 216). Le acompaña un elenco de personajes jóvenes, masculinos y femeninos, que forman el grupo els peripatètics. En general, la serie propone una mirada predominantemente masculina. Se aprecia un mayor desarrollo de los personajes varones, en número, variedad y profundidad de sus perfiles. Estos parten del estereotipo: el guapo, el gay en el armario, el gracioso, el niño de mamá, etcétera y evolucionan hasta abandonar esas características iniciales por unas nuevas adquiridas gracias al profesor durante el transcurso de la narración. En el caso de las protagonistas femeninas las personajes poseen menos atención y se acercan más al estereotipo. Paradójicamente, la serie propone un discurso novedoso y liberador sobre la sexualidad, y vincula las relaciones sexuales al pensamiento crítico porque consigue que lo sexual sea un tema más para pensar (Alcalá, Rodríguez \& Solórzano, 2018:92). Además, Merlí asume la tendencia actual de incorporar papeles con mayor diversidad de orientaciones sexuales: en la serie se representan heterosexuales, homosexuales y bisexuales. Además de visibilizar el colectivo LGTBIQ, escasamente representado en las pantallas españolas (Marcos, González de Garay \& Arcila, 2020).

En lo audiovisual la serie apela al lenguaje clásico de los seriales, con un empleo de la cámara transparente, un montaje sencillo que busca la continuidad y una composición realista en la escala de planos. En ocasiones se recurre al montaje paralelo para explicar secuencias que ocurren en distintos lugares al mismo tiempo y a las transiciones elíptico temporales con imágenes de la ciudad de Barcelona en distintos momentos del día para contextualizar la acción y señalar el paso del tiempo. En estas aparece una lechuza que funciona como referencia a la sabiduría y al mundo griego, cuna del pensamiento crítico de la filosofía occidental. Sobre las innovaciones se destaca el uso de la música clásica como banda sonora que cumple una función descriptiva y narrativa (Millà, 2019); y un opening que nos sumerge en el ambiente escolar de la filosofía mediante imágenes de pupitres, pizarras, libros, esquemas didácticos o conceptos ligados a la etapa juvenil. El vuelo del moscardón de Rimski-Kórsakov musicaliza la cabecera en donde se nos presenta a su protagonista, en plano medio, delante de un encerado que muestra un esquema ontológico de la filosofía. Una mosca-que vuela, copula, pasea sobre el material didáctico, se posa en el café y finalmente subraya el nombre de Merlí- acompaña el discurrir de esta pieza, ofreciendo pistas sobre el carácter irritante de su protagonista.

El seguimiento de Merlí provocó la aparición de otros productos culturales que ampliaron la narrativa de la serie hacia el ámbito transmedia. Los lunes, tras la emisión del episodio de estreno y antes de uno de reposición, TV3 programó el 
programa de televisión Merlinari (TV3, 2017), donde parte de los intérpretes de la serie se adentraban en un instituto real para hablar con estudiantes sobre los temas que se habían planteado en la ficción. Además, Héctor Lozano publicó en la editorial Planeta de Atresmedia el libro: Cuando fuimos los peripatéticos, y en Grijalbo: El libro de Merlí:filosofía y merlinadas que te harán flipar, con la autoría de Rebecca Beltrán. A estos se añadió después la novela Yo, Pol Rubio (Crossbooks, en castellano y Columna, en catalán), que ampliaba la historia de la nueva serie.

\section{Skam España. Tecnología y reflexión social femenina para jóvenes}

Skam España es una serie producida por Zeppelin TV (Endemol Shine Iberia) emitida en una plataforma de pago: Movistar+. Dirigida por Begoña Álvarez y José Ramón Ayerra y escrita por Beatriz Arias, Jon de la Cuesta y Estíbaliz Burgaleta, como coordinadora de guiones. Se observa un equipo creativo mayoritariamente femenino en sintonía con la propuesta original. Porque esta serie es una adaptación de la producción noruega Skam (vergüenza) -4 temporadas, 43 episodiosemitida por la cadena pública NRK. La serie fue un éxito de seguimiento en el país nórdico, y su eclosión global coincidió con el estreno de su tercera temporada, en otoño, 2016. La producción surge de la propia cadena noruega, que observaba cómo decrecía en su audiencia el número de espectadores jóvenes (Bengtsson, Källquist \& Sveningsson, 2018). Se le encarga el proyecto a Julie Andem, directora y guionista del INRK P3, canal estatal enfocado a la cultura juvenil. Andem no concretó la narrativa hasta realizar un proceso etnográfico que implicó la realización de entrevistas a adolescentes noruegos en diferentes institutos (Sabina, de la Fuente \& Martínez, 2019).

Skam España es una teen serie que apunta a audiencias juveniles. Movistar+ adquirió sus derechos para la producción española en 2017 y la estrenó un año más tarde. El equipo responsable de la adaptación española se planteó como objetivo reflejar de forma fidedigna la juventud española actual, y para ello realizaron una labor de campo previa, con entrevistas a estudiantes de institutos para conocer sus inquietudes y motivaciones.

La serie sigue la propuesta argumental planteada en la versión original con mínimos cambios en tramas y personajes, y propone guiños específicos para su adaptación a la audiencia española. La historia cuenta la vida de un grupo de compañeras que cursan el bachillerato en un instituto de Madrid. Un descubrimiento novedoso es el recurso narrativo del cambio de perspectiva del relato que se produce en cada nueva temporada. Este planteamiento sirve para componer un relato polifónico, que amplía el abanico de identificaciones y representaciones. Gracias a ello el espectador puede profundizar en las protagonistas comprendiendo sus contextos y empatizando con sus conflictos. Con el cambio del personaje protagonista la deriva de la serie se expande, desatendiendo a unos personajes para incrementar la atención en otros nuevos o hasta entonces secundarios. Las chicas protagonistas no se encuadran en estereotipos, y reflejan una sociedad compleja en sus relaciones con sus pares masculinos y femeninos, mientras que la trascendencia narrativa de los personajes adultos es residual y cumplen funciones de complemento.

Consecuente con su núcleo de protagonistas, la serie ofrece una perspectiva femenina. El tema fundamental que atraviesa es la amistad entre mujeres, desmarcándose del planteamiento manido en ficciones anteriores donde los personajes femeninos dependen narrativamente de los hombres y tienden a rivalizar entre ellas. Skam España propone una representación femenina moderna, alternativa, próxima a la realidad. Esquiva la presentación sexualizada de los cuerpos 
femeninos y los presenta bajo un prisma naturalista que aspira a la autenticidad, aunque a veces no la consiga. Una de las protagonistas (Nora) se sirve de este marco para exponer conceptos feministas que se proyectan en el entorno y van calando en el resto de compañeras hasta imponer un discurso de sororidad que protege al grupo y lo ayuda para resolver los conflictos y las diferencias que se establecen entre ellas.

Entre los temas que se tratan aparecen tópicos propios de la edad y otros que no son de patrimonio exclusivo de los adolescentes. La serie propone y debate sobre asuntos dispares como la religión-musulmana-, la celotipia, los discursos del odio o los trastornos mentales. También ahonda en otros, como el abuso entre pares, los usos negativos de las redes sociales, las relaciones sentimentales dañinas o el descubrimiento de las identidades sexuales. Lo relevante de la ficción es que trata de responder a través de sus personajes y sus valores -de amistad, tolerancia, generosidad- de forma integradora, tratando de que el espectador tome conciencia de las problemáticas y ofreciéndole recursos para afrontar e imponerse sobre estas. "Lejos de ser moralizante, el propósito de Skam es construir una serie que cuida de sus historias y personajes trasladando valores positivos de respeto y humanidad a los espectadores. En el sitio web \#thankyouskam se recogen multitud de mensajes anónimos de agradecimiento a la serie" (Lozano, 2018).

La estética de la serie es pretendidamente intimista, con un lenguaje próximo al género documental -rodada con cámara al hombro, recurriendo a los primeros planos, el silencio como recurso narrativo o la iluminación naturalista- que casa con el concurso de un reparto inédito en la experiencia previa en la actuación. Cada episodio se compone de distintas secuencias que aluden a diferentes momentos temporales. Estos comienzan in media res y finalizan con un fundido a negro. Sobreimpresionada sobre el plano oscuro se fija la marcación temporal-día, hora-que contextualiza el inicio de los clips y también distingue Skam, el título de la serie que se lee en amarillo fluorescente a todo ancho de pantalla.

Otro aporte fundamental de la serie es la manera de contar la historia, que trasciende de la emisión habitual televisiva para ofrecer nuevas alternativas a su visionado. Skam España ensanchó las posibilidades apostando por la transmedialidad. En la página http://skamespana.movistarplus.es se cuelgan a tiempo real las distintas secuencias en las que se divide el episodio semanal. Todos estos capítulos están completados por mensajes de WhatsApp, así como contenidos publicados en las cuentas de Instagram de los personajes -y que no vemos en el montaje final de capítulo-. Esta apuesta por la emisión desde las redes sociales se redobló durante la segunda temporada con la iniciativa de subir los clips a Youtube sin restricciones geográficas y permitiendo la incorporación de subtítulos, lo que ayudó al aumento de visitas y resonancia de la serie (López, 2019). También supuso anotar una dimensión más sobre el desarrollo de los personajes, incrementando con ello el acercamiento a la realidad.

El fenómeno Skam se ha propagado en un corto espacio de tiempo. A partir del 2018 no sólo se produjo la adaptación española, también se han realizado varias temporadas de Skam France (2018); la versión alemana, titulada Druck (2018); Skam Austin en Estados Unidos (2018); Skam Italia; Skam NL, en los Países Bajos y wtFock, que fue como se tituló el remake de Bélgica. Todas las adaptaciones realizan variaciones en el contenido para adecuarlas a la idiosincrasia de cada territorio. Sin embargo, el formato transmedia de la emisión es común a todas las versiones. 


\section{Discusión y conclusiones}

De los resultados obtenidos y del contraste de estos con los antecedentes se concluye que las series de televisión juveniles españolas han experimentado una renovación. Los canales y las plataformas VOD han facilitado el acceso a las producciones de tal manera que los espectadores pueden visionar los contenidos en diferentes dispositivos y en cualquier momento. La propuesta de Skam España implementa un nuevo progreso, al dividir los episodios en escenas y emitir estas de manera fragmentada a través de las redes sociales, acompañándolas de mensajes, chats, fotografías o vídeos. Esta proposición cumple una función complementaria a la difusión convencional que ayuda a desarrollar los personajes de forma alternativa y permite al público una inmersión más profunda en la historia. Algo parecido sucede con las novelas y libros publicados alrededor de Merlí. También aquí se emplean los textos para acceder a reflexiones de los personajes, para profundizar en su mundo y posibilitar una prospectiva sobre ellos. En estas nuevas propuestas la forma transmedial se emplea como conector entre los relatos y su difusión sobre las audiencias jóvenes. Se entiende que articular el relato aprovechando este mix de lenguajes y prácticas que emplean los jóvenes -internet, televisión, redes sociales, comunidades de fans, libros, novelas- puede ser fructífero para la propagación de las ficciones televisivas e igualmente provechoso para las audiencias activas, puesto que esta arquitectura audiovisual aviva la creatividad y ensancha el debate sobre los temas y las ideas que se expresan en las ficciones.

Los caminos comerciales de estas nuevas series son diferentes y peculiares. Si bien las dos fueron concebidas y emitidas en primera instancia por televisiones públicas (TV3 catalana y NRK noruega), la tendencia a la globalización cultural de la televisión y el poder de convocatoria de ambas han propiciado que las dos hayan terminado -al menos en España-por formar parte de los catálogos de plataformas VOD (Netflix y Movistar). Este itinerario da cuenta de las estrategias comerciales de los emisores: de una parte, apuestan por creadores y creadoras de series de éxito y les ofrecen medios para realizar obras destinadas al mismo público. De otra parte, se observa la agilidad de televisiones y plataformas para captar formatos populares. Esto sucede con Skam, con adaptaciones en múltiples países; y también con Merlí, que reinterpreta por enésima vez el planteamiento del profesor o la profesora polémica que emplea técnicas pedagógicas poco ortodoxas para motivar a los estudiantes. Un argumento atractivo, en vigencia, como lo demuestran las tres temporadas de Merlí y su posterior spinoff, además de HIT (TVE, 2020), la última producción de TVE que ensaya una nueva variación de esta misma sinopsis.

La forma de contar las historias cambia y se acondiciona al presente. Son contenidos que buscan la autenticidad, historias y personajes ligados a la realidad. Emplean una jerga juvenil, reiterativa, espontánea, propia de la clase social que representan. Persiguen la representatividad: contextos familiares diversos, personajes religiones diferentes, sexualidades alternativas, estudian o trabajan, situados en centros educativos públicos y en espacios urbanos reconocibles.

Estas series abordan temas actuales y se sirven de ellos para componer tramas y personajes. El feminismo permea en Skam España y sus personajes. Estas, tras unos inicios vacilantes, se acercan al modelo de mujeres empoderadas. Las relaciones entre protagonistas superan la representación tradicional y conservadora de los papeles femeninos para mostrar nuevos modelos, que priman valores como la amistad, la tolerancia o la integridad. 
La regeneración de los personajes también se produce con la representación de personas al margen heteronormativo, exponiendo condiciones sexuales y formas de ser diversas. Estas series visibilizan una parte de la realidad LGTBIQ, lo que contribuye a la normalización. Lo interesante no es tanto el planteamiento del tema como que los personajes sean introducidos de forma orgánica en la trama

En el planteamiento de las nuevas series de televisión juveniles el propósito era seducir a adolescentes y el reclamo, más que intelectual, era formal, por lo que se apelaba al reparto artístico, a la mezcla de géneros, a los giros inesperados de la historia. Sin embargo, estas nuevas producciones tienen la voluntad de crear conciencia crítica en los públicos a los que se dirige. Son series que transmiten mensajes transformadores e integradores, relacionados con el eduentretenimiento, en sintonía con otras producciones extranjeras como la chilena El reemplazante (TVN, 2012), la estadounidense Atypical (Netflix, 2017) o la británica Sex Education (Netflix, 2019). Aunque para ello alteren las estéticas buscando un lenguaje intimista, como sucede en Skam, o recurran a enunciados provocativos, como en Merlí.

La heterogeneidad de estas dos propuestas y sus dispares recorridos comerciales no impiden apreciar que la innovación en la ficción televisiva adolescente se produce de forma indistinta en obras originales o en adaptaciones. Tanto Merlí como Skam España comparten características que se vinculan a la calidad de la televisión pública: son producciones de ficción que entretienen y además proponen innovación en el relato, compromiso con la sociedad y reflexión. Series, en suma, que fomentan el cambio social positivo a través de sus personajes y argumentos, que apuestan por la integración, por el reconocimiento a las diferencias personales y culturales, y que valoran el público -en este caso juvenil- más allá de su rentabilidad comercial.

\section{Referencias bibliográficas}

Alcalá, F.; Rodríguez, Z. y Solórzano, F. (2018). La sexualidad en la serie de TV3 Merlí: una propuesta liberadora. El ojo que piensa. Revista de cine iberoamericano, núm. 17, 79-95.

Bazán, V. y Sastre, P. (2014). El verano azul de Curro Jiménez: la recuperación de programas de cine en TVE. Cuadernos de documentación multimedia, núm. 25, 90-100. https://doi.org/10.5209/rev_CDMU.2014.v25.47477

Bengtsson, E.; Källquist, R. y Sveningsson, M. (2018). Combining new and old viewing practices. Uses and Experiences of the transmedia series 'Skam'. Nordicom Review, 39, 2, 63-77. https://doi.org/10.2478/nor-2018-0012

Bermejo, J. (2012). Los personajes y las series de ficción en la vida de los y las jóvenes. Revista de Estudios de Juventud, núm. 96, 31-49.

Bonavitta, P. y de Garay, J. (2019). La casa de papel, Rita y Merlí: entre nuevas narrativas y viejos patriarcados. Investigaciones feministas, vol. 10, núm. 1, 207-221. https://doi.org/10.5209/infe.66490

Casetti, F. y di Chio, F. (1999). Análisis de la televisión. Instrumentos, métodos y prácticas de investigación. Paidós: Barcelona. Cohen, J. (2006). Audiencia identification with media characters. En Bryant, J. y Vorderer, P. (eds): Psychology of entertainment, pp. 183-197. Mahwah, NJ: Lawrence Erlbaum Associates. 
Crespo, M. (2005). Mensajes y modelos televisivos para los adolescentes: estudio base para un análisis sistemático del contenido sexual de las series de televisión. Doxa, núm. 3, 187-214. https://doi.org/10.31921/doxacom.n3a11

Figueras, M.; Tortajada, I. y Araüna, N. (2014). La erótica del malote. Lecturas adolescentes de las series televisivas: atracción, deseo y relaciones sexuales afectivas. Revista de Estudios de Juventud, núm. 106, 49-62.

Galán, E. y del Pino, C. (2010). Jóvenes, ficción televisiva y nuevas tecnologías. Área Abierta, núm. 25, 1-17. https://dx.doi. org/10.5209/ARAB

García, N. y Fedele, M. (2011). Las series televisivas juveniles: tramas y conflictos en una teen series. Comunicar, núm 37, 133-140. https://doi.org/10.3916/C37-2011-03-05

García, P. (2011). Lo geek vende. Transformaciones de los topoi sobre adolescente inadaptado en las series de televisión norteamericanas. FRAME, núm. 7, 159-190.

González, S. (2012). La representación de la violencia en las series juveniles españolas. Comunicación, núm. 10, 943-957.

Grande, V. (2019). Una mayor empatía al VIH/sida a través de la educomunicación. Revista española de comunicación en salud, 10 (1), 102-108, https://doi.org/10.20318/recs.2019.4577

Guarinos, V.; Gordillo, I.; Ramírez, M., et. al (2010). Masculinidades de ficción televisiva y retroalimentación online. Jóvenes y adolescentes en-red-ados fuera y dentro de Física o química y El internado. Ponencia en el II Congreso Internacional de la AE-IC. Disponible en t.ly/wsZ5

Guarinos, V. (2009). Fenómenos televisivos teenagers: prototipias adolescentes en series vistas en España. Comunicar, núm. 33, 203-211. https://doi.org/10.3916/c33-2009-03-012

Gutiérrez, C. (2019). La relación entre los creativos independientes de la televisión pública y la audiencia infantil. Anagramas rumbos y sentidos de la comunicación, 18 (35), 39-55. https:// doi.org/10.22395/angr.v18n35a3

Heintz-Knowles, K. E. (2000). Images of youth: a content analysis of adolescents in prime time entertainment programming. Frameworks Institute: Washington, DC.

Hidalgo-Marí, T. y de la Cuadra, E. (2020). Familias en la ficción televisiva ante el cambio de siglo: una comparativa entre producciones dramáticas y comedias. Estudios sobre el mensaje periodístico, 26 (2), 635-644. https://doi.org/10.5209/ esmp.67488

Hoffner, C. y Buchanan, M. (2005). Young adult's wishful identification with televisión characters: the role of perceived similarity and carácter attributes. Media Psychology, núm. 7, 325-352. https://doi.org/10.1207/S1532785XMEP0704_2

Jinadasa, M.P.K. (2015). Teen culture: a production of modern popular televisión and new media text. Peradeniya University International Research Sessions-2015. iPURSE Proceedings, Vol. 19.

Lacalle, C. (Ed.) (2013). Jóvenes y ficción televisiva. Construcción de la identidad y transmedialidad. Editorial UOC: Barcelona.

Llanos, H. (4 de noviembre de 2018). De 'Al salir de clase' a 'Élite', Carlos Montero lleva dos décadas haciendo series adolescentes. El País. Disponible en t.ly/7rDa 
López, M. (3 de junio de 2019). 'Skam España’ y su apuesta por la visibilidad. No submarines. Disponible en t.ly/UMis Lozano, J. (2018). La importancia de 'SKAM': nuevas narrativas tecnológicas y sociales. Fuera de series. Disponible en t.ly/ SsY8

Marcos, M.; González de Garay, B. y Arcila, C. (2020). Grupos minoritarios en la ficción televisiva española: análisis de contenido y percepciones ciudadanas para la creación de un índice de diversidad. Cuadernos.info, (46), 307-341. https:// doi.org/10.7764/cdi.46.1739

Martínez, J. L. y Rodó de Zárate, M. (2020). El efecto Merlí: televisión y elección de grados universitarios relacionados con la filosofía. Athenea Digital, vol. 20, núm. 1, 1-24. https://doi.org/10.5565/rev/athenea.2453

Masanet, M. J.; Medina, P. y Ferrés, J. (2012). Representación mediática de la sexualidad en la ficción seriada dirigida a los jóvenes: estudios de caso de Los protegidos y Física o Química. Comunicación, núm. 10, 1537-1548.

Mateos-Pérez, J. (2012). La programación infantil y juvenil en el cambio de ciclo televisivo español (1990-1994). Palabra Clave, núm. 15 (3), 524-548.

Medrano, C.; Aierbe, A. y Martínez de Moretin, J. I. (2011). Valores percibidos en el medio televisivo por adolescentes en contextos transculturales. Comunicar, núm. 37, 117-124. http://dx.doi.org/10.3916/C37-2011-03-03

Millà, M. (2019). Música clásica, serious music o música culta en la serie de televisión: Merlí. Ni graffiti del presente, ni estampida del pasado. Popular Music Research Today, vol. 1, núm. 1, 89-102. http://dx.doi.org/10.14201/pmrt.19174

Navarro, Y. y Climent, J. A. (2014). El efecto socializador del medio televisivo en jóvenes. Influencia de las conductas de gestión del conflicto mostradas por personajes de series de ficción. Área Abierta, vol. 14, núm. 1, 25-42. https://dx.doi. org/10.5209/ARAB

Pindado, J. (2006). Los medios de comunicación y la construcción de la identidad adolescente. Zer, vol. 11, núm. 21, 11-22.

Raya, I.; Sánchez-Labella, I. y Durán, V. (2018). La construcción de los perfiles adolescentes en las series de Netflix Por trece razones y Atípico. Comunicación y Medios, núm. 37, 131-143. http://doi.org/10.5354/0719-1529.2018.48631

Sabina, J.; de la Fuente, J. y Martínez, R. (2019). El ecosistema mediático juvenil en España: un estudio de caso sobre el fandom de la serie Skam. En López, N. y Medina de la Viña, E. (coords.) Comunicación y pensamiento. Relatos de la nueva comunicación, pp. 33-51. Egregius: Sevilla.

Solà, P. (14 de diciembre de 2015). No puedes tomarte 'Merlí' como si fuera un documental sobre los institutos. La Vanguardia. Disponible en t.ly/GroU

Villa, N. (2012). Televisión, jóvenes y políticas públicas. Aspectos clave de una relación que contribuye al desarrollo social. Revista científica de Educación y Comunicación en la Sociedad del Conocimiento, 12 (1). http://doi.org/10.30827/eticanet. v12i1.16828 